LA-UR-

\title{
EFFECT OF UNSYMMETRIC MISSILE FORCE REDUCTIONS
}

Author(s):

Gregory H. Canavan, DDP

Submitted to:

For discussions outside the Laboratory

Date: June 1997

\section{Los Alamos}

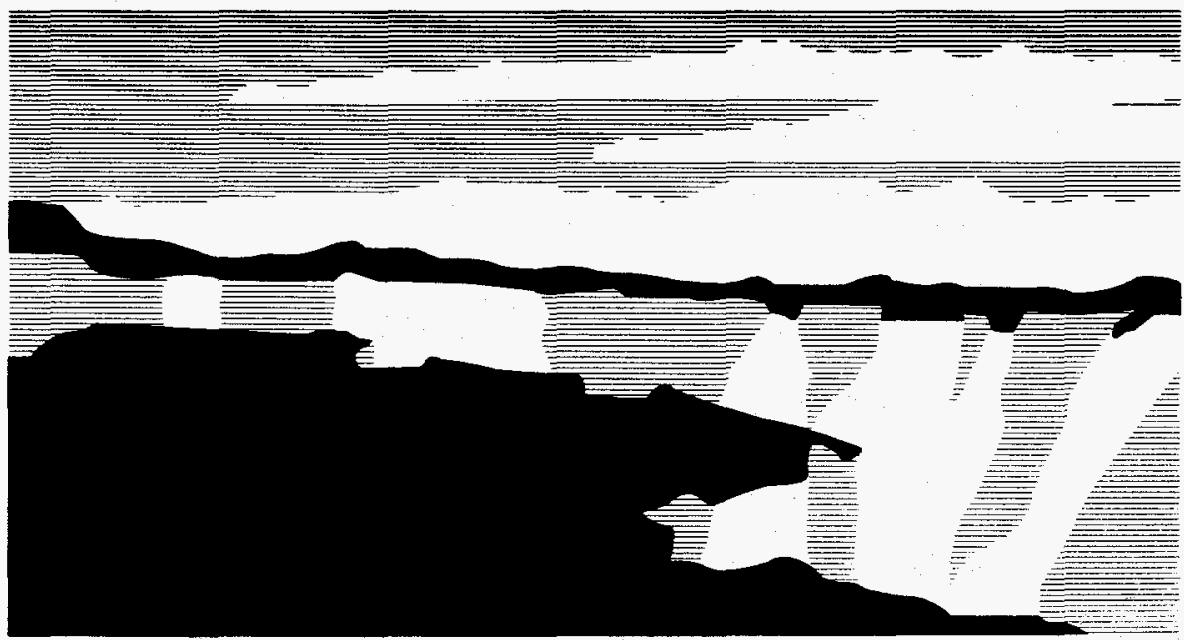

Los Alamos National Laboratory, an affirmative action/equal opportunity employer, is operated by the University of California for the U.S. Department of Energy under contract W-7405-ENG-36. By acceptance of this articte, the publisher recognizes that the U.S. Government retains a nonexclusive, royalty-free license to publish or reproduce the published form of this contribution, or to aliow others to do so, for U.S. Government purposes. The Los Alamos Natjonal Laboratory

requests that the publisher identify this article as work performed under the auspices of the U.S. Department of Energy. 


\section{DISCLAMMER}

Portions of this document may be illegible in electronic image products. Images are produced from the best available original document. 


\title{
EFFECT OF UNSYMMETRIC MISSILE FORCE REDUCTIONS
}

\author{
Gregory H. Canavan
}

Unilateral reductions from START I levels fall unevenly on the two sides. The side that reduces forces experiences a significant drop in first and second strike capability and increasing strike costs, in exchange for which both he and his opponent experience increases in stability indices.

This note discusses the effect on first strike stability of unsymmetric force reductions, i.e., unilateral reductions from START I levels by one side only. It uses the model for unsymmetric force exchanges, damage, costs, and indices derived in earlier notes. 1,2 It discusses the effect on first strike stability of unsymmetric force reductions, i.e., unilateral reductions from START I levels by one side only, using the models for unsymmetric force exchanges, damage, costs, and indices derived in earlier notes. The forces treated are approximations that are assumed to fall in equal decrements from START I to II levels. Attack allocations are determined numerically because of the large initial forces. They are relatively insensitive to fractionation. The decreasing side's average allocation is about 0.5 ; the static side's allocation is about 0.25 .

This model leads to exchanges in which the static side's first and second strikes are about constant and the decreasing side's first and second strikes drop roughly in proportion to his decreasing fractionation. By the end of the transition, the static side could inflict about a factor of 2 more damage by striking firs, but the decreasing side could only achieve parity by striking first. The static side's second strike costs fall to his first strike costs. The decreasing side's first strike costs rise toward his second strike costs, but do not reach them by START II level forces. At the end of the transition the static side rises to unit stability while the side whose forces decrease $50 \%$ increases to about 0.8 stability. The primary effect for START levels is that decreasing vulnerable forces increases the cost of striking first, which penalizes the decrease, and decreasing survivable forces reduces the second strike, which reduces the cost of striking to the static side. Thus, the essential trade is a large reduction in the damage that could be done by either for about equal amounts of self-deterrence and incentivization of the other.

Forces. The two sides are denoted as in the earlier notes by unprime and prime, whose missile forces are taken to roughly resemble those of the U.S. and Russia. In this study the U.S. is assumed to reduce its forces unilaterally from START I levels to START II levels and configurations while the Russian missile forces do not change. The number of unprime land based ICBMs remains at $M=500$, but the average number of weapons per missile decreases from $m=4$ to 1 in 8 equal decrements, which can roughly be associated with annual changes. Unprime's submarine warheads decrease from 4,000 to 2,800 . They are assumed to be on a 
number of $m=10$ warhead missiles that decreases from 400 to 280 ; however, that fractionation does not impact the stability calculations below. Overall, unprime's forces fall from 2,000 vulnerable warheads and 4,000 survivable warheads to 500 vulnerable singlet warheads and 2,800 survivable warheads for a total of about 3,300 . As both $\mathrm{m}$ and $\mathrm{N}$ are taken to fall in equal increments, $\mathrm{N}$ is known for any given $\mathrm{m}$, so $\mathrm{m}$ alone can be used as an index of the extent of reduction below.

Primes forces remain throughout at $M^{\prime}=500$ missiles with $\mathrm{m}^{\prime}=10$ weapons each and $\mathrm{N}^{\prime}$ $=100$ SLBMs with $\mathrm{n}^{\prime}=10$ weapons each. Thus, primes forces remain at 5,000 vulnerable warheads and 1,000 survivable warheads.

The reduction in unprime's vulnerable forces means that this shift increases the asymmetry in vulnerable versus survivable forces between unprime and prime. Bombers are not included in the assessment above. For attacks with little warnings, they could be destroyed prior to launch with only a few weapons, so they would not alter the results below. With a great deal of warning they could be dispersed for survivability where the number required would be about and order of magnitude larger. However, even than number would be well below the inventories discussed above.

Exchange. Previous notes have shown that the allocations, $f$ and $f^{\prime}$, of each side's missile weapons to the other side's vulnerable missiles are important features of exchanges. In the previous paper, the allocation was performed with an analytic optimization derived earlier. ${ }^{3}$ In this study, the numbers of weapons are large enough that the allocation is determined by the simultaneous numerical iteration of $f$ to minimize unprime's first strike cost $\mathrm{C}_{1}$ and of $\mathrm{f}^{\prime}$ to minimize unprime's first strike cost $\mathrm{C}_{1}$ '. Figure 1 shows $\mathrm{f}$ and $\mathrm{f}^{\prime}$ as functions of $\mathrm{m}$ for the forces described above. Unprime's allocation $\mathrm{f}$ increases from about 0.46 to 0.54 , which means unprime would target about $20 \%$ more weapons on vulnerable missiles at the end of the transition. This numerical allocation is within $10-20 \%$ of the analytic optimization for $m<2$, i.e., under 4,000 weapons. Prime's allocation $f$ increases slightly during the middle of the transition and then falls slightly as $\mathrm{m}$ approaches 1 . The analytic allocation would fall by a factor of 2 .

Figure 2 shows the resulting first and second strikes possible by both sides. The top line is prime's first strike, which changes little because his allocation $f^{\prime}$ changes little. The second curve down is unprime's second strike, which is essentially just his (declining) number of submarine weapons, as prime typically allocates almost 3 weapons per ICBM, so few survive to participate in the second strike anywhere in the transition. That result is somewhat sensitive to the kill probability of $p=0.6$ used for both sides. The third curve is unprime's first strike, which decreases with the decrease in weapons per ICBM, SLBMs, and increased allocation to missiles. The bottom line is prime's second strike, which is small because of the smallness of his ICBM force, which permits unprime to target about 5 weapons on each missile. 
Costs. Figure 3 shows the first and second strike costs for unprime and prime as functions of $\mathrm{m}$. At the right side of the chart, the bottom curve is unprime's first strike cost, which rises from about 0.44 to 0.54 . It increases because from Fig. 2, unprime's first strike is falling rapidly while prime's second strike increases slightly. The curve above it is prime's first strike cost, which decreases slightly because the magnitude of unprime's second strike falls. The next curve is unprime's second strike cost, because his second strike falls with the number of SLBMs. The top curve is prime's second cost, which falls strongly for $\mathrm{m}<2$ because unprime's first strike falls with $\mathrm{m}$.

Stability Indices. Figure 4 shows the individual stability indices $I=C_{1} / C_{2}$ for unprime and $I^{\prime}=C_{1}{ }^{\prime} / C_{2}^{\prime}$ for prime and $I x I^{\prime}=\left(C_{1} / C_{2}\right)\left(C_{1} / C_{2}\right)$ for them both. For $m=4, I \approx 0.66$ and $I^{\prime}$ $\approx 0.87$, so the initial overall stability is only about 0.58 . At the end of the transition when $\mathrm{m}=1, \mathrm{I}$ $\approx 0.79$ and $\mathrm{I}^{\prime} \approx 0.1$, so the final stability index is about 0.8 . That is a more than $20 \%$ increase, which is positive, and there are apparently contributions from the increase of both $I$ and $I$. By the end of the transition, prime has unit index, which means he is indifferent to striking first or second, although unprime's and the overall index is only about 0.8 . While both indices increase, Fig. 3 shows that $I$ increases because unprime's $C_{1}$ increases towards his already large $C_{2}$, while I' increases because $\mathrm{C}_{2}$ ' falls towards $\mathrm{C}_{1}$ '. That is, prime's stability increases because the cost of striking second decreases, not because the cost of striking first increases, as is the case with unprime. These costs in turn reflect the force exchanges of Fig. 2, which show that prime's first and second strikes increase slightly while unprime's first and second strikes both fall strongly.

Summary and conclusions. This discusses the effect on first strike stability of unsymmetric force reductions, i.e., unilateral reductions from START I levels by one side only, using the models for unsymmetric force exchanges, damage, costs, and indices derived in earlier notes. The forces treated are aggregated approximations to START level forces, which are assumed to fall in equal decrements from START I to II levels.

Attack allocations are determined numerically because of the large forces at the outset. They are relatively insensitive to fractionation. The decreasing side's average allocation is about 0.5 ; the static side's allocation is about 0.25 . This leads to exchanges in which the static side's first and second strikes are about constant and the decreasing side's first and second strikes drop roughly in proportion to his decreasing fractionation. By the end of the transition, the static side could inflict about a factor of 2 more damage by striking firs, but the decreasing side could only achieve parity by striking first.

The static side's second strike costs fall to his first strike costs. The decreasing side's first strike costs rise toward his second strike costs, but do not reach them by START II level forces. At the end of the transition the static side rises to unit stability while the side whose forces decrease $50 \%$ increases to about 0.8 stability. The primary effect for START levels is that 
decreasing vulnerable forces increases the cost of striking first, which penalizes the decrease, and decreasing survivable forces reduces the second strike, which reduces the cost of striking to the static side. Thus, the essential trade is a large reduction in the damage that could be done by either for about equal amounts of self-deterrence and incentivization of the other.

\section{References}

1. G. Canavan, "Stability of Unsymmetric Forces," Los Alamos National Laboratory report LAUR-97-1133, March 1997.

2. G. Canavan, "Attack Optimization for Unequal Moderate Forces," Los Alamos National Laboratory report LA-UR-97-, June 1997.

3. G. Canavan, "Attack Optimization for Unequal Moderate Forces," op. cit.

\section{DISCLAIMER}

This report was prepared as an account of work sponsored by an agency of the United States Government. Neither the United States Government nor any agency thereof, nor any of their employees, makes any warranty, express or implied, or assumes any legal liability or responsibility for the accuracy, completeness, or usefulness of any information, apparatus, product, or process disclosed, or represents that its use would not infringe privately owned rights. Reference herein to any specific commercial product, process, or service by trade name, trademark, manufacturer, or otherwise does not necessarily constitute or imply its endorsement, recommendation, or favoring by the United States Government or any agency thereof. The views and opinions of authors expressed herein do not necessarily state or reflect those of the United States Government or any agency thereof. 


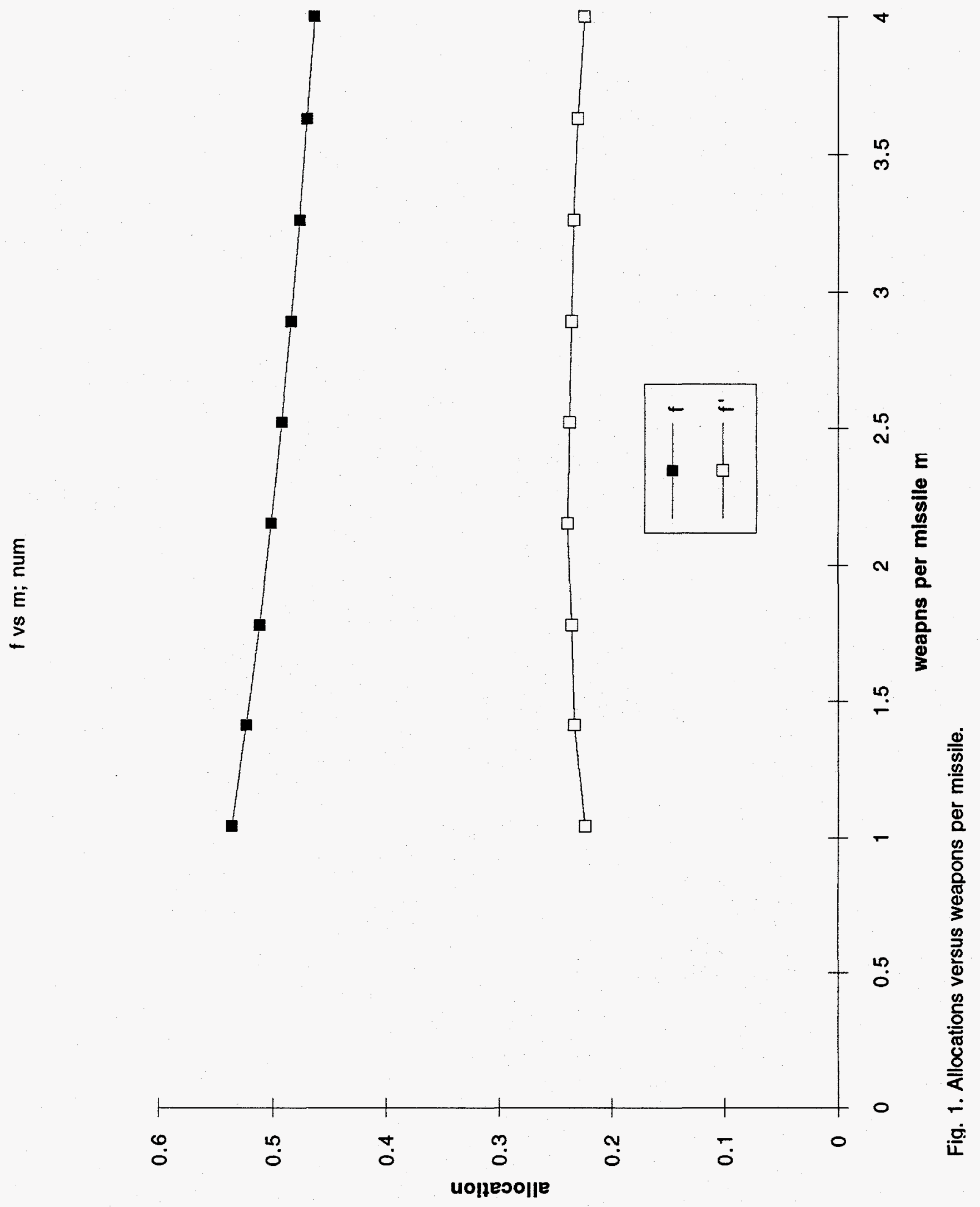




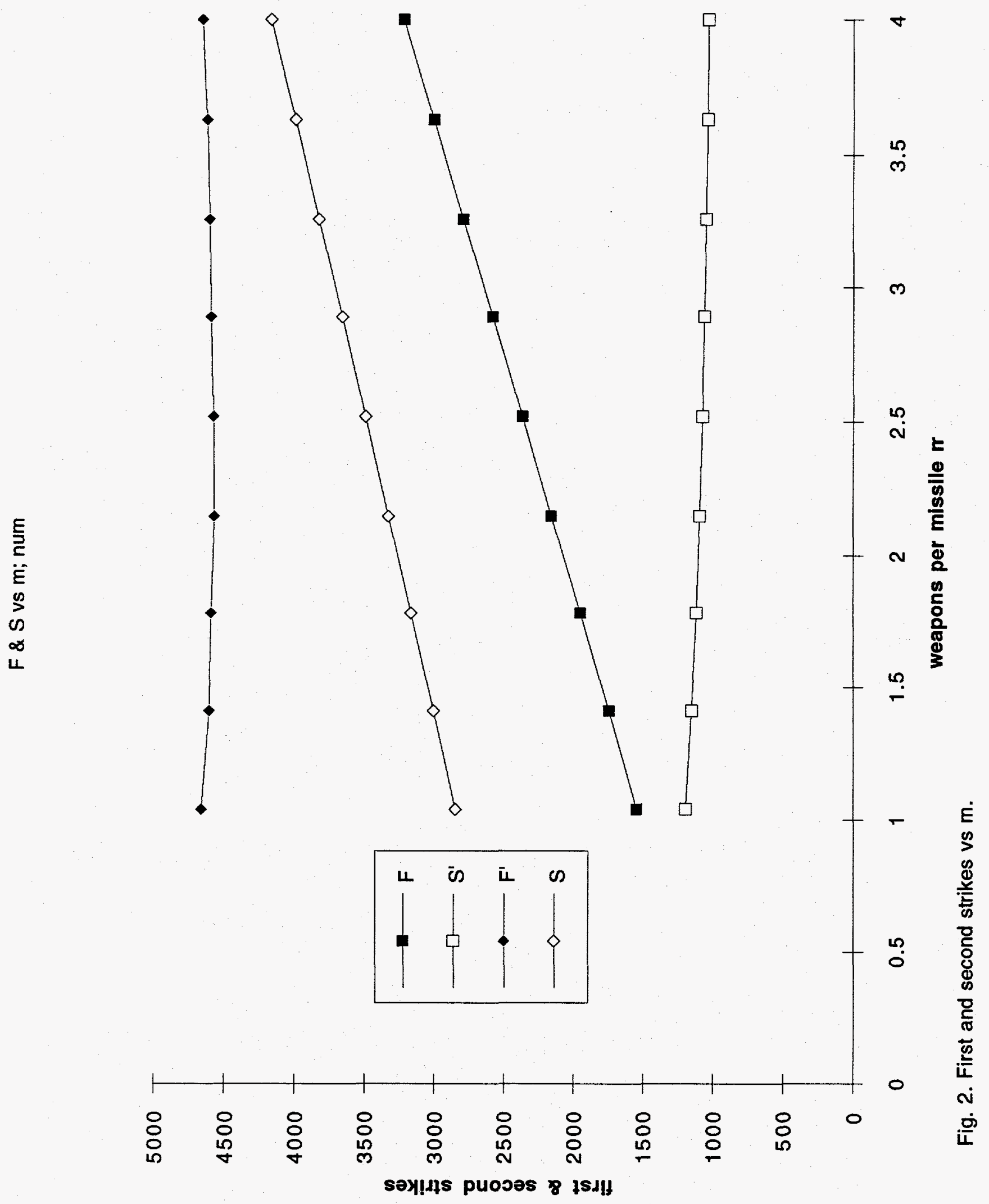




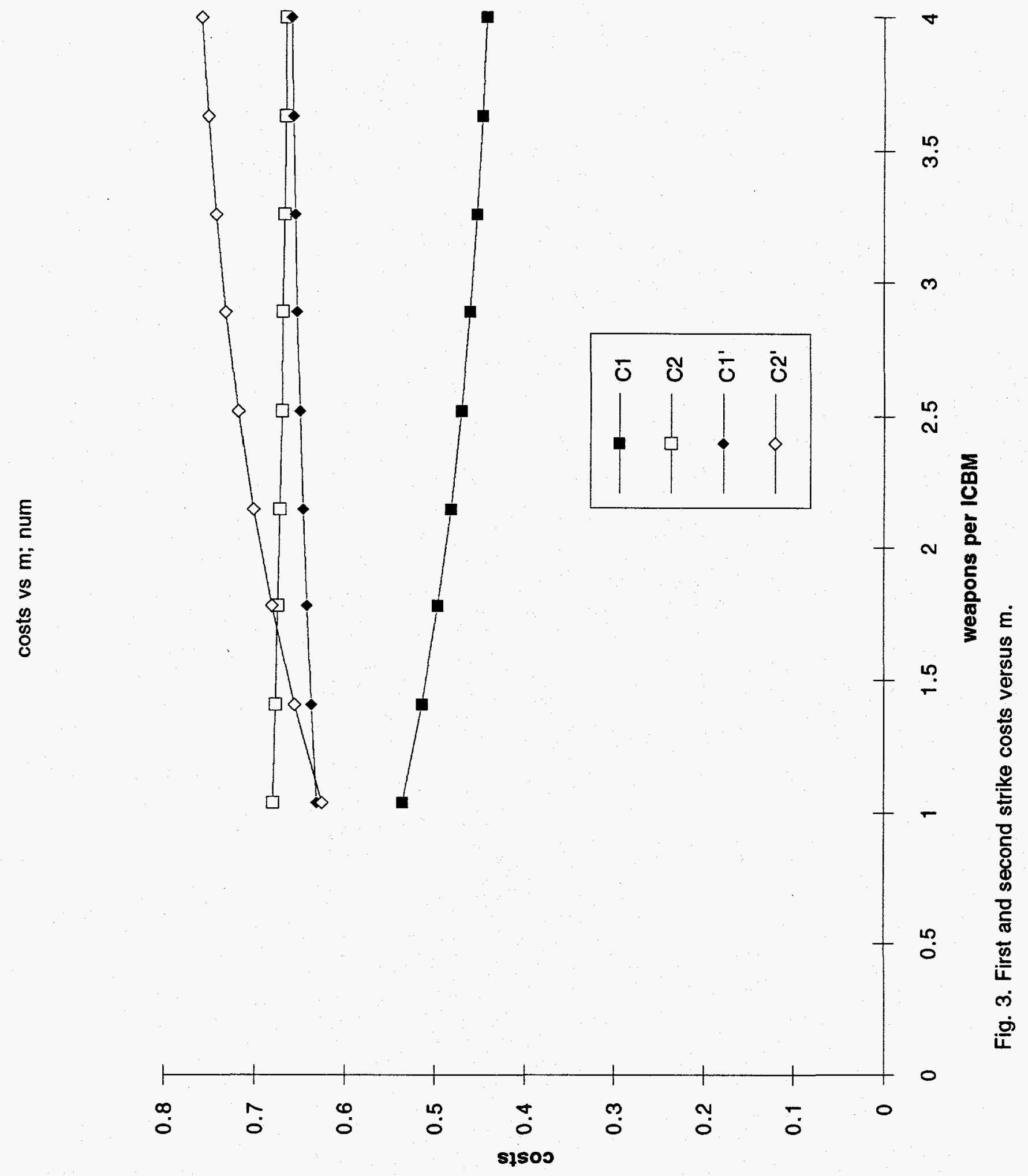




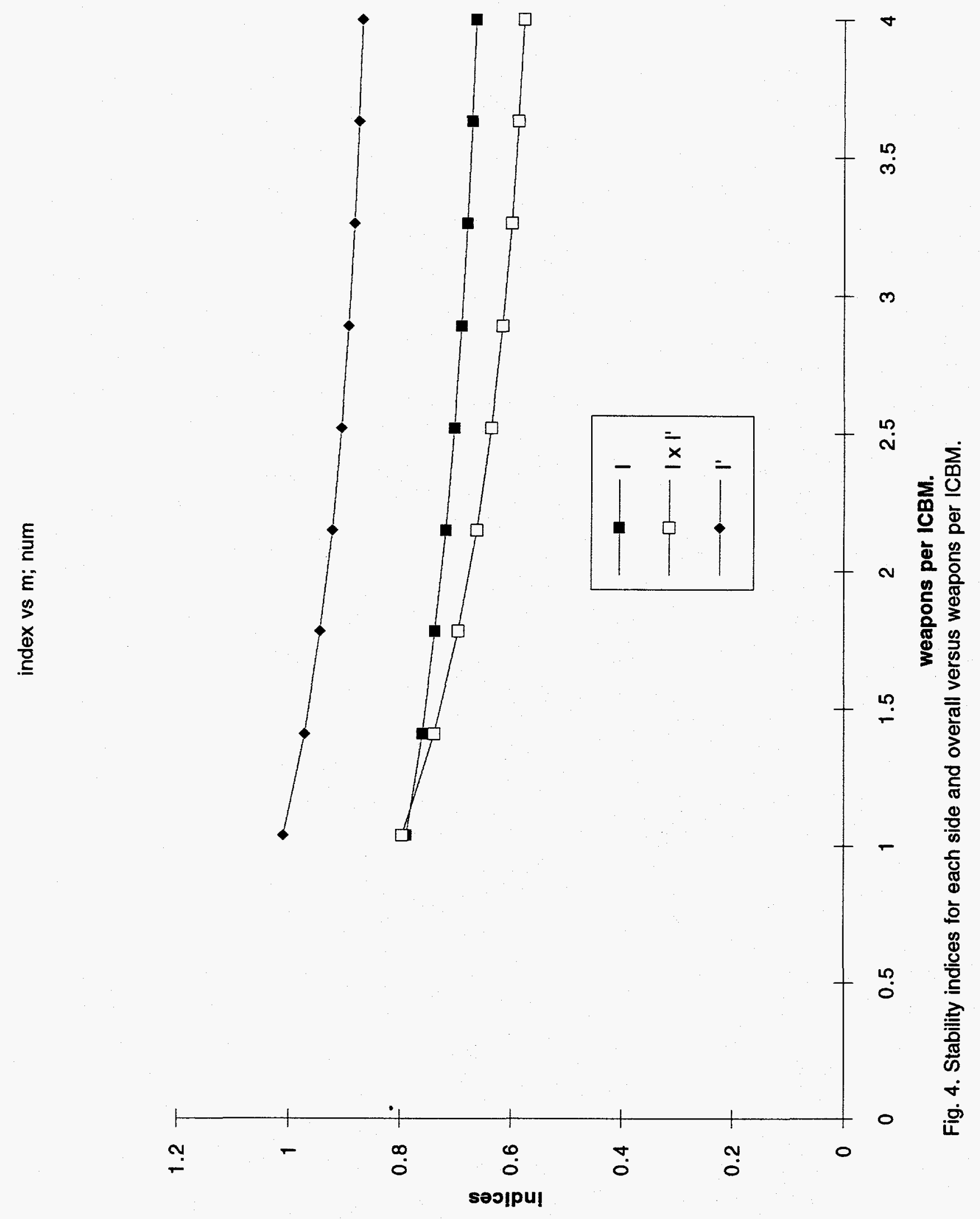

